\title{
Governing through community-based research: Lessons from the Canadian HIV research sector
}

\author{
Adrian Guta ${ }^{\text {a, }}$, , Carol Strike ${ }^{b}$, Sarah Flicker ${ }^{c}$, Stuart J. Murray ${ }^{a}$, Ross Upshur ${ }^{\text {b }}$, \\ Ted Myers ${ }^{b}$

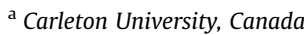 \\ ${ }^{\mathrm{b}}$ University of Toronto, Canada \\ ${ }^{\mathrm{c}}$ York University, Canada
}

\section{A R T I C L E I N F O}

\section{Article history:}

Available online 12 July 2014

\section{Keywords:}

Citizenship

Community-based research

Community-based participatory research

Foucault

Governmentality

Situational analysis

HIV/AIDS

Canada

\begin{abstract}
A B S T R A C T
The "general public" and specific "communities" are increasingly being integrated into scientific decision-making. This shift emphasizes "scientific citizenship" and collaboration between interdisciplinary scientists, lay people, and multi-sector stakeholders (universities, healthcare, and government). The objective of this paper is to problematize these developments through a theoretically informed reading of empirical data that describes the consequences of bringing together actors in the Canadian HIV community-based research (CBR) movement. Drawing on Foucauldian "governmentality" the complex inner workings of the impetus to conduct collaborative research are explored. The analysis offered surfaces the ways in which a formalized approach to CBR, as promoted through state funding mechanisms, determines the structure and limits of engagement while simultaneously reinforcing the need for finer grained knowledge about marginalized communities. Here, discourses about risk merge with notions of "scientific citizenship" to implicate both researchers and communities in a process of governance.
\end{abstract}

( $) 2014$ The Authors. Published by Elsevier Ltd. This is an open access article under the CC BY-NC-ND license (http://creativecommons.org/licenses/by-nc-nd/3.0/).
“Civil society is, I believe, a concept of governmental technology..."

(Foucault, 2010a, 296)

Globally, the traditional lines between users and producers of knowledge have become blurred as lay people are increasingly participating in research through what has been termed "citizen science" (Bonney et al., 2014). Proponents of this new relationship between science and society have advanced the concept of the "scientific citizen" who actively participates and contributes to scientific forums (Bickerstaff et al., 2010; Irwin, 2001). Here, citizenship rights are enacted through active participation in the production and consumption of science (Bäckstrand, 2003; Elam and Bertilsson, 2003; Jackson et al., 2005). This shift has received support from policy circles, in part, to ease public concern following high profile scientific controversies, and the general lack of transparency from the scientific community (Mayer, 2003; Wynne,

\footnotetext{
* Corresponding author. Faculty of Arts \& Social Sciences, Carleton University, 1125 Colonel By Drive, Ottawa, ON K1S 5B6, Canada.

E-mail address: Adrian.Guta@Carleton.ca (A. Guta).
}

2006). Early AIDS activism provides a classic example of the public confronting the "established moral and epistemic authority" of researchers (Elam and Bertilsson, 2003, 245). These activists protested the closed door culture of public scientific institutions, pharmaceutical companies, and government regulatory bodies to demand greater transparency and accountability (Epstein, 1996). Their actions have since been credited with disrupting scientific hegemony and creating a template for other social movements (Altman, 1994; Silversides, 2003). Subsequently, new mechanisms have been established to increase public involvement and democratize decision-making in a range of health related issues (Boivin et al., 2010; Mitton et al., 2009; O’Doherty and Burgess, 2009). The growth of scientific citizenship is evident in lay representation on research advisory boards and membership on research teams (Silvestre et al., 2010; Simon et al., 2011). However, there have been calls to move further along the spectrum of engagement from consultation to leadership.

An area where there have been significant attempts to engage the public, and key communities, is in health research (Ahmed and Palermo, 2010; Jones and Wells, 2007; Lavery et al., 2010). In an attempt to better understand the needs of communities affected by health issues, "community-based participatory research (CBPR)" 
has emerged as an alternative research and evaluation paradigm (Israel et al., 1998; Wallerstein and Duran, 2006). CBPR requires establishing "a research topic of importance to the community with the aim of combining knowledge and action for social change to improve community health and eliminate health disparities (W.K. Kellogg Foundation's Community Health Scholar's program, cited in Minkler and Wallerstein, 2008, 6). Though "community" is a complex and contested term (Jewkes and Murcott, 1998), here it includes those directly affected by a health issue and allies working in service provision and advocacy roles (Green and Mercer, 2001). This approach actively engages researchers, clinicians, and communities in the development of health research, program evaluations, and social and clinical interventions (Green et al., 2001; Kone et al., 2000; Minkler, 2005). CBPR projects have adopted a range of research designs and methodological techniques to promote inclusion and generate data (Israel et al., 2005). Community-based approaches to health research have been credited with producing more useful and relevant research results than would have been possible through traditional investigator driven research approaches (Minkler, 2005). There is evidence that these kinds of initiatives are improving medical and public health research and practice (Jagosh et al., 2012; Viswanathan et al., 2004). Consequently, funding has become available in the United States (see National Institutes of Health; The Centers for Disease Control and Prevention, 2011) and Canada (see Canadian Institutes of Health Research, 2009).

While community engagement in health research has arguably gone "mainstream" (Horowitz et al., 2009), important concerns have been raised that strategies to engage the public in scientific decision-making are being used to pre-empt criticism and actively shape opinion. Braun and Schultz (2010) have argued that target stakeholder groups are constructed for the purpose of engagement, which fosters certain kinds of dialogues while precluding others. These initiatives presume that engagement is important and necessary, but they often use instrumental techniques for soliciting this engagement (Barnett et al., 2012). Within community-based research various stakeholders may have different understandings of engagement, capacity building of community members, and the role of the research itself (Roche, 2008). Particularly concerning is that public dialogue may be used to screen out more opinionated individuals and produce bureaucratized and sanitized versions of public dialogue (Gregory and Lock, 2008, 1261). Despite the nostalgic praise for early AIDS organizing, the resulting 'partnerships' between communities, scientists, and the state, have been charged with producing a bureaucratic structure that undermines the movement's original goals (Comaroff, 2007; Guta et al., 2011).

In developing their typology of citizen science Wiggins and Crowston (2011, p. 1) note a focus in the literature on the steps of participation over "sociotechnical and macrostructural factors influencing the design and management of participation." The current study aims to address this gap by examining the influence of such factors on the Canadian HIV community-based research (CBR) movement, using it as a site to read the ways different discourses, programs, and technologies operate to prescribe the terms of "scientific citizenship." With decades of development the HIV sector provides an important case with implications for those conducting community-based research in other health sectors. This paper starts with an overview of the Canadian HIV CBR movement, an introduction to the theoretical framework we use to guide our analysis, the methods, and a theoretically guided presentation of the results. Our goal is to surface previously unexamined sociotechnical and macrostructural factors that govern scientific citizenship.

\section{The Canadian HIV community-based research movement}

Communities affected by HIV were amongst the first to demand community input into the research process (Schensul, 1999). The involvement of people living with and affected by HIV in research and policy decision making is now common practice (Chung and Lounsbury, 2006; Mosavel et al., 2005; Rhodes et al., 2010). In Canada this has led to partnerships between HIV sector stakeholders and university-based researchers to conduct "communitybased research" (Harris, 2006). HIV CBR involves the participation of community members living with and affected by HIV as partners and co-learners in the research process (Allman et al., 1997). Researchers have partnered with community stakeholders to develop appropriate research designs and data collection procedures, making it possible to effectively research sensitive and stigmatized topics (Bauer et al., 2012; George et al., 2012; Greene et al., 2010; Logie et al., 2012b; McClelland et al., 2012). This research movement has been credited with taking important steps towards "democratizing" HIV research (Ogden, 1999) and promoting the "greater involvement of people living with HIV" (GIPA) (Travers et al., 2008).

In Canada this work is supported by the Canadian Institutes of Health Research (CIHR) through a unique "HIV/AIDS Communitybased Research Program." The CIHR enables much of the health research infrastructure across the country. The HIV CBR funding program has recognized the historical legacy of community involvement in HIV research and now "supports research that engages communities in all stages of research, from the definition of the research question, to capacity building and integration of community members in conducting research, to active participation in disseminating research results" (CIHR, 2012a). The CIHR (2012a) defines CBR as:

... a collaborative approach to research that equitably involves all partners in the research process and recognizes the unique strengths that each brings. CBR begins with a research topic of importance to the community with the aim of combining knowledge and action for social change to improve community health and eliminate health disparities. CBR brings researchers together with members of the community to: identify the issues; collect, analyze and interpret the data; and decide how to use the results to inform policy, change practice and improve conditions in the community.

This program was designed to assist community-based and nongovernmental organizations "in developing the knowledge they need to carry out their work in the most effective manner and in creating research expertise within these organizations" (CIHR, 2012). In recognition of the disproportionate burden of HIV infection amongst Aboriginal peoples in Canada, the program has a "general" and "Aboriginal stream." The program is governed by a steering committee comprised of "equal representation of HIV/ AIDS CBR researchers and broader community organizations" (CIHR, 2012). Each grant proposal is evaluated with "equal weight" for its "potential impact and scientific merit" (CIHR, 2012). In all, the CIHR HIV CBR funding program is a sophisticated example of integration between academics, communities, and government funders to conduct health research.

The CBR program is emblematic of the CIHR's (2009, 14) commitment to "citizen engagement" through "the meaningful involvement of individual citizens in policy or program development." In the CIHR's $(2009,15)$ terminology, "the term 'citizen' includes interested representatives of the general public, consumers of health services, patients, caregivers, advocates and representatives from affected community and voluntary health 
organizations." In their "framework for citizen engagement," the CIHR $(2009,29)$ has identified CBR as an important tool and have recommended more funding opportunities to encourage these collaborations. Because it is well-established, the Canadian HIV CBR movement is a rich site to critically examine the implications of scientific citizenship, as operationalized through state sponsored funding structures, on various stakeholders in academia and the community. To assist us in theorizing the implications of community engagement in HIV CBR we turn to Michel Foucault (1988), whose writings examined the production of the 'truth' through scientific and institutional discourses and their general deployment in the shaping of social order.

\section{Theorizing community engagement in research}

Foucault $(1978,92)$ is known for his conception of power as dynamic, relational, and productive. Power is not centralized, but is exercised by various actors to achieve certain ends. Foucault (2003a, 138) used the concept of "governmentality" (or, the "conduct of conducts") to investigate the ways power inserts itself into actions, attitudes, and discourses to determine individual and collective conduct. Foucault (2007, 108-109) defined governmentality as "the ensemble formed by institutions, procedures, analysis and reflections, calculations, and tactics that allow the exercise of ... power that has the population as its target, political economy as its major form of knowledge, and apparatuses of security as its essential technical instrument...." The specifics of these three factors - political economy, population, and securitization are historically and contextually mediated. In the modern epoch, governmentality has been orchestrated through neoliberalism, a political economic rationality that merges economic analysis with a theory of human capital and entrepreneurship (Foucault, 2010a, 218-219). Here, the population is conceived of as "an object of surveillance, analysis, intervention, modification, etc." in need of regulation (Foucault, 1980, 171). The population's productive potential is ensured through seemingly neutral social institutions (e.g., education, medicine, public hygiene, etc.), which, through their collective intervention and direction, form an "apparatus of security" (Foucault, 2007). Governmentality has been used to theorize the relationships between macro political and economic forces, various state and social institutions, and the practices of individuals in their daily lives (Burchell et al., 1991; Dean, 2010; Hamann, 2009). In all, governmentality has inspired many to think differently about taken-for-granted systems and institutions, with an eye to what they enable or constrain.

In his later writings Foucault $(2005,252)$ expanded governmentality to account for "power relationships in the broadest and not merely political sense of the term," stating that "power relations, governmentality, the government of the self and of others, and the relationship of self to self, constitute a chain, a thread [through which] we should be able to connect together the question of politics and the question of ethics." This is not just political and juridical governance, but the government "of children, of souls, of communities, of families, [and] of the sick" (Foucault, 2003a, 138). Foucault (2010a, 296) even characterized civil society, usually espoused as central to democracy, as a "governmental technology." Foucault's framing of all relationships as sites of power and governance troubled his critics, but inspired others to think in creative and novel ways about health in modern times (Petersen, 2003). Specifically, Foucault's work has been highly influential in theorizing the emergence of the active health citizenship promoted by states in recent decades, where individuals have become constructed as entrepreneurs of their own health and wellness (Bunton and Petersen, 1997). In advanced western economies earlier models of health care and public services have been re-organized to achieve the neoliberal goals of cost effectiveness, individualization, and responsibilization (McGregor, 2001; Teghtsoonian, 2009; Woolford and Curran, 2013). Patients, service users, and health care providers alike, become governable through their relationship to the health care system and health services (Flynn, 2002; Fries, 2008; Holmes and Gastaldo, 2002; Waring, 2007), and ultimately, through their relationships to each other.

In Foucault's (2010b, 3) terms, HIV provides an important "focal point of experience" in "which forms of possible knowledge (savoir), normative frameworks of behavior for individuals, and potential modes of existence for possible subjects are linked together." Foucault's work has been used to interrogate the production of medical and public health knowledge in relation to HIV (Finn and Sarangi, 2008; Lupton and Tulloch, 1998; Mykhalovskiy et al., 2004), and the deployment of that knowledge to govern the health, hygiene, and sexual practices of individuals and collectivities deemed to be at risk (Geary, 2007; Nguyen, 2010; Parker and Aggleton, 2003). Most relevant to our analysis, Miller and Rose $(2008,92)$ identified early AIDS organizing as an example of "governing through community," which "involves a variety of strategies for inventing and instrumentalizing [the] dimensions of allegiance between individuals and communities in the service of projects of regulation, reform, or mobilization." They argue that the shift to 'community' as a site of intervention by the state reflects a neoliberal re-organizing of society into sites of difference that can be "investigated, mapped, classified, documented, [and] interpreted" (Ibid, 89). Recently, Guta et al. (2013) have considered the ways community is constructed for research purposes, and how community interests may clash with the need to produce evidence. With this in mind, we turn to the Canadian HIV CBR movement to examine the current relationship between neoliberal governance, HIV, the production of evidence, and community need. Next we describe our empirical study and present results from qualitative interviews.

\section{Methods}

Data were collected as part of the multi-stage, Canada-wide, research study that examined ethical issues in community-based research in Canada. Participants were recruited using a publicly available list of recipients of the CIHR HIV CBR operating grants. A purposive sampling strategy was developed based on a publically available list of recipients of the CIHR HIV CBR operating grants. The goal was to reflect Canadian regional diversity and the priority populations identified in national policy documents (e.g., injection drug users, men who have sex with men, etc.). In total, 50 interviews were conducted with HIV CBR practitioners from across Canada. The final sample includes 35 "academic" participants (university-based researchers, clinician scientists, and graduate students) and 16 "community" participants (researchers housed in community-based organizations). Participants differed in terms of their training, lived experience in relation to HIV, and their involvement with the HIV movement, but were all actively involved in HIV CBR. We provide a breakdown of where interviews were conducted (see Table 1) but we do not provide more detailed

Table 1

Participant demographics.

\begin{tabular}{lcc}
\hline & Total & $\%$ \\
\hline Interviews & 50 & $100 \%$ \\
Provinces & & \\
British Columbia & 9 & $18 \%$ \\
Alberta/Prairies & 9 & $18 \%$ \\
Ontario & 22 & $44 \%$ \\
Quebec & 6 & $12 \%$ \\
Atlantic Provinces (Maritimes) & 4 & $8 \%$ \\
\hline
\end{tabular}


demographics for several reasons. First, although participants were asked to discuss the projects they led, many chose to discuss the range of HIV CBR projects in which they were or had been involved as collaborators or co-investigators. Second, some researchers could be identifiable by listing their unique study topic. Finally, while participants are marked with an " $\mathrm{A}$ " for "academic" and a " $\mathrm{C}$ " for "community," these labels do not necessarily reflect their training or lived experience. For example, many academic participants described themselves as members of the communities they worked with (e.g., gay men, Aboriginal, etc.), and had themselves worked in community-based organizations. The community participants had graduate degrees, some had experience working at universities and at hospitals, and all had considerable research experience. These labels best represent the participants' professional role at the time of the interview.

Semi-structured interviews were conducted between May 2010 and July 2011 and interviews lasted between one-to-three hours. Interview questions were drawn from the literature and the research team's experience with HIV CBR. The interview questions contained four sections asking questions: about the participants' training and experience; how they became involved in their respective project(s); how the ethics review process unfolded; and what kinds of issues emerged over the "life" of the project. Participants were asked to reflect on how the project team came together, on the project's decision-making structures, and how 'community' was conceptualized in their project(s) (e.g., who was engaged). Participants were asked to reflect on the ethical issues in their work, as they defined them, with consideration for various aspects of their project's research design (e.g., chosen methods, sampling and recruitment strategy, analysis, etc.). All participants were asked the same general set of questions, with probes tailored to explore their situated perspective. Due to the geographic distribution of participants, half of the interviews were conducted by telephone. Participants were asked for, and provided, consent to be interviewed and digitally recorded. Interviews were transcribed verbatim and data imported into NVivo 9 qualitative data management software. Ethics review for this study was received from York University, Wilfrid Laurier University, St. Michael's Hospital, the University of Toronto, McGill University, the University of Calgary, and Dalhousie University. Standard informed consent procedures were followed.

\section{Analysis}

The analysis was undertaken in a two stages. Stage 1: Involved the development of 11 major codes and 81 sub-codes. Codes were developed from close readings of the data to identify important themes. The codes were discussed by the research team at a twoday data analysis retreat where each member was given a complete printed code (based on their interest/experiences) and asked to review and present it to the larger group. The group collectively discussed the analytic possibilities created by our coding strategy and made recommendations. Considering the research team's significant experience in the area of HIV CBR, we understand this process as a form of 'member-checking.' The data were further analysed independently as part of the lead author's doctoral project using insight from Clarke's $(2005,55)$ "situational analysis" (SA). SA reconciles grounded theory with Foucauldian theory to empirically map the relationship between actions, discourses, and practices.

Using Dean's (2010, 33) "analytics of government" we considered the relationship between visibility, truth, intervention, and subject formation to further our analysis. Drawing on Miller and Rose (2008) we reinterpreted standard practices in the CBR literature (e.g., empowerment, capacity-building, partnership building, etc.), and some specific to the Canadian HIV CBR movement (e.g., policy relevance), as "technologies of government." These technologies of government establish connections "between the aspirations of authorities and the activities of individuals and groups" through diffuse techniques of standardization, specialization, expertise, examination and calculation, and especially collecting information about the population (Miller and Rose, 2008, 63-83). Finally, we integrated "'practical texts' that provide rules, opinions and advice on how to behave in a certain fashion" (Winch, 2005, 181 ) in the form of CIHR funding guidelines. We further considered issues identified in the literature, such as constructing 'need' and the role of funding in shaping community engagement initiatives (Conway et al., 2007). This stage involved iteratively reading the coded data with an attention to governing actors from above (e.g., through formal funding policies) and how they govern each other (e.g., through accountability mechanisms).

Governmentality is flexible and can be used in combination with various other methods, but requires a commitment to creativity and a critical ethos to investigation (Rose et al., 2006). In respect to quality, Walters (2012, 141-143) has identified strengths and limitations with using governmentality to map power relations: mapping can take an infinite number of routes and reveal landscapes of power, but maps are not neutral and can conceal as much as they reveal. Dean $(2010,33)$ has argued that an analytics of government is "perspectival" and "there is no absolute standard of truth by which this analytics can be judged." Rather, its intelligibility is determined by comparing it to other accounts of the same phenomenon. However, when using an SA approach which blends grounded theory and Foucauldian insights, Clarke (2005, 12-14) has called for reflexivity and an acknowledgement of the role of the analyst in shaping the analysis. We acknowledge that our goal in this paper is to challenge and disrupt some popular but undertheorized claims about CBR. Having been involved in HIV CBR in various capacities, ours is an "insider critique" in the tradition of Cooke and Kothari (2001) who interrogated taken-for-granted aspects of participatory development by drawing on their practice experience. Our goal here, in keeping with Foucault's own project, is to offer a "problematization" that we hope will lead to further discussion and debate. The subsequent analysis presents a critical encounter between an ideal type of CBR presented in CIHR policies, the perspectives of practitioners who conduct this type of research, and theoretical interpretations from the governmentality literature.

\section{Results}

Our results are presented in a way that follows the progression of the individual interviews - from asking participants to reflect on the inception of their project to discussing issues that emerged during the course of conducting this work. We start by examining how community 'need' necessitated research and demonstrate how a funding mechanism designed to promote community engagement makes certain kinds of research and relationships possible. In the next section we explore issues that emerged over the 'life' of these projects to demonstrate the consequences of bringing together various stakeholders with divergent interests and the limits of community engagement. Following the presentation of results we revisit our theoretical framework, and more recent contributions to the literature, to raise critical questions about the implications of scientific citizenship as operationalized through community-based research.

\section{Problematizing 'need'}

Participants were asked to describe how they became involved in their respective CBR projects and their planning and organizing phases. Many participants invoked the popular claim that CBR 
should be community-initiated, address relevant needs, and have an action-centred social change agenda, as promoted in the literature (Minkler and Wallerstein, 2008) and in the CIHR HIV CBR (2012a) funding description:

My approach has always been to respond to community needs and so rather than pursuing my own research agenda, I respond to community invitations to be involved in different projects.... [It] was, grounded [in] the community need, and their articulated need for the research, and they basically said 'we want this done'. (Interview 12, A)

This popular sentiment served to position the academic as benign and lacking personal motivations except to, as some participants put it, "serve" community. However, the historical legacy of earlier research that failed to meet community needs, or further stigmatized them, left some communities "suspicious":

Communities out there are very ... suspicious of researchers ... they [community members] are like 'So ... after that, what next? You are here just like any other ones that we have seen come and take all these things and go' ... particular communities feel they are just too over-researched and they don't want you to take anymore. (Interview 10, C)

Suspicion of researchers had to be overcome through negotiations where community-based organizations needed to be convinced of the benefits of research:

We [academics] saw the value of community-based research in terms of its potential to be informing programs and policies at the community level but this is the first [time that] the community we [were] dealing with had engaged in research to this extent. I wouldn't say necessarily mistrust but due to those cultural differences there were a lot of reservations on the side of the organization to be getting involved ... they wanted to ensure that in signing up for the study ... that they have a say in all the decision-making and of course that is what defines community based research but again that's just something that needed a lot of back and forth discussion to be able to clarify the roles and responsibilities.... (Interview 34, A)

This tension between community "need" and "suspicion" brings into question claims made by proponents of CBR who promote the importance of research but often fail to reflect on the impetus behind the inducement to research (Israel et al., 2001). Next, we see that moving beyond suspicion raised new issues.

\subsection{Funding and the conditions of possibility}

With growing "opportunities" for community-based organizations to participate in evidence production, their participation has signalled its own evidence of change in the service sector. Participation demonstrates that organizations are efficient and accountable to their client and community stakeholders. However, what has been framed as addressing the community's 'need' for research serves to produce knowledge about the community:

I think community is invested in these projects because ... these results help them figure out how many people a year are visiting and what their needs are, and help them argue for more funding in the provincial government as well or from the health authorities. (Interview 31, A)
While these funds were targeted for research, they were sometimes used to maintain programs, staff, and service levels. This next academic participant reflected on her previous experience working in the community for years, and offered a more candid explanation for partnering than is usually documented in the literature:

Money! I need money! That's the honest truth. It's so hard to get core funding for service organizations if you don't have statistics to back it up. The other is it's easier to get research dollars than it is to get core funding, so we could actually, again, as a community-based research project, we're actually providing a service at the same time. (Interview 9, A)

This relationship between government and community-based organizations was rarely problematized, and many participants took the availability of funding as "serendipitous." This participant weighs the opportunity to conduct research and the requirement to provide government funders with evidence of need to continue funding the organization's programs:

Well it was a combination of things, it was the opportunity, [and] it was the need. We needed the information, we had to have something to come back with to the government, then the opportunity came to apply for funding, and we had a group of [community] people who were beginning to see they had a role ... the thing for funding would come across my desk and I'd fire it off to the [executive director] of one of the different organizations and say, 'you know we should apply for this...' [to] support their other project proposals that they were putting in, it was serendipity.... (Interview 7, A)

While these organizations freely participate in this process, failing to do so may mark them as uncompetitive in the eyes of funders. Especially when they are compared to other organizations who are conducting their own research and can demonstrate evidence of their effectiveness and ongoing need from the communities they serve.

\subsection{Managing partnerships}

Challenging the claim that communities intrinsically want leadership roles in research, and that research is a "tool" for community-based organizations, this academic questioned whether communities are even interested in knowledge production:

I'm generalizing, and I'm sure there are agencies who do, but some of them have gotten into wanting to be the primary holder of [research] funds because the project money has dried up [and] they're looking to research as a way to sustain them, not because they're really that interested in being the primary researchers. That's my personal opinion. (Interview 13, A)

This quotation challenges the claim that community-based organizations want leadership roles on research projects, but also highlights a tension over who holds the funds. This next participant described the possibility of exploitation as a result of the pressure to obtain funding. First, he recounted an experience of being engaged by community solely for his credentials and later reflected on researchers exploiting community:

In one grant, they signed me up, you know, used me as the research expert, to shake loose the funds. I think they invited me 
to one meeting in the summertime, when I was away on my summer holidays and I never heard from them again..

... there [are] too many examples of researchers saying all the right things to get community groups to endorse their so-called community-based research. Then they get the money and they bugger off and community never sees them again, and they have little control or influence over the actual research. (Interview 2 , A)

In an attempt to prevent abuses and demonstrate authenticity, many partnerships adopt a formal "memorandum of understanding" signed by each of the partners (see Chau et al., 2007). This next participant described the usefulness of this approach:

... one of the first things we did was to start fleshing out a memorandum of understanding that helped to clarify the roles and responsibilities of each co-applicant ... for us to refer back to anytime there is any type of confusion or in order ... to try and hammer out the logistics of management. (Interview, $34 \mathrm{~A}$ )

However, another participant questioned whether these documents just contribute to the research bureaucracy:

You have to do that. It bores me to tears.... If you don't have a good relationship with your partner ... no memorandum of understanding, no prenuptial, will make it better, nothing. So, yes I do it because it's part of a bureaucracy, some of the tools we use.... (Interview 17, C)

These results highlight the ways in which funding processes codify a supposed "need" through formal research "partnerships." This orientation to partnership and engagement reflects the neoliberal "competitive contractualism" that has been affecting community organizations for some time (Larner and Craig, 2005, 409). The approaches discussed here are further evaluated through granting review processes where the "quality" of individual research partnerships is scrutinized and compared against others with ever growing expectations.

\subsection{Growing expectations}

The participants in this study were all recipients of CIHR HIV CBR operating grant program which required they "engag[e] communities in all stages of research" (CIHR, 2012a). This next academic participant described this as an unrealistic expectation:

... and you must be working with people through the whole process of design, analysis, interpretation, dissemination, which is great, it's just not that practical. I don't know many people in communities interested in that. But I think there is this huge gold standard [in] CBR ... you either do all of these and you're CBR or you don't do all of them and you're not CBR. (Interview $37, \mathrm{~A})$

This sentiment was echoed by another participant who argued this approach to research assumes a certain interest and ability that may not reflect the realities of community members' lives:

I think there's a presumption that there's a particular CBR model that works, right? I don't think that every kind of community member comes with a particular level of education, or expecting every researcher to emulate or be able to perform in that manner, [it assumes] that everybody has the time, the inclination and the ability to participate as an equal partner, I think it is wrong, and sometimes you get comments [from grant reviewers] like that, there's an expectation that you can do that and that's not true.... (Interview 38, A)

This next participant explained how funding proposals, despite having come from otherwise strong community partnerships, are ranked poorly if they do not demonstrate the Greater Involvement of People Living with AIDS (GIPA) principle in certain ways:

They've got people from universities working with ASOs [AIDS service organizations], and they have tight connections working with a lot of those organizations. They are admired in the community but then when you send these [proposals] to a committee to review ... you don't get the money because you 'don't have enough GIPA in there.' Well for me a lot of that GIPA is understood at the grassroots level because that's where we have been for the last 10 years. (Interview 49, A)

Yet, the expectation to demonstrate increasing levels of community engagement was rarely supported with the necessary resources:

I think there's still an expectation that community-based research can be done on the cheap. While I think it is far more expensive than, or just as expensive as clinical research, or epidemiological research. I'm happy to do all [that engagement] as long as there's money. (Interview 17, C)

However, the responsibility for making up funding shortfalls often fell onto the community partners:

... the project was funded on quite a shoestring budget, it required us to be quite creative and for a lot of people to be working in-kind, and I think that at this point it's been a lot of work for the community partners, they weren't aware that it was going to be this much work. (Interview 24, A)

While it would be easy to blame the funder for developing unrealistic expectations, these requirements were determined with academic and community representatives, and continue to be promoted by reviewers from both camps in each funding competition. Successful applicants become the reviewers in subsequent years and reproduce these expectations.

\subsection{From quality data to 'real world' impact}

An additional requirement of funding is that findings will inform program and broader policy change (CIHR, 2012a). For many participants this made sense as part of the research/practice cycle:

My whole intention of getting the information that I was looking to essentially turn it into programming and because of my role, co-existing as [an investigator] in this project and also a program coordinator, I did have the ability to do that, where any information that I got I would be able to turn directly into programming. (Interview $1, \mathrm{C}$ )

Having evidence to prove what programs work is understood as a precondition for "real" policy change, and is increasingly tied to research funding objectives. Research teams must convince reviewers, in advance of conducting the research, that it will have some kind of real world impact. This next participant reflected on the implications for conducting research with policy goals: 
The issues that we choose to study always reflects that there is some tangible thing in terms of policy, there are programs that [have] to come out of it. I am not saying there should be no policy or program outcomes, I think we need research to support the decision-making about policy, programs, etc.... but in this work we do, people think well if there's not some policy then you're wasting your time. (Interview 15, C)

Finally, this next participant raised questions about where this emphasis on policy came from and whether it was actually community initiated:

I think there's ... a story that has sort of evolved into that collaborative stuff. A few years ago at the [x] conference, somebody from Health Canada stood up and said very authoritatively that 'the purpose of CBR was to inform policy.' And I thought 'it is?' ... it all got sort of co-opted you know? (Interview $11, \mathrm{C})$

The premise is that having the "right" kinds of evidence, framed appropriately and delivered to the right audience, will result in policy change. However, this often ignores the highly politicized nature of policy-making (Macnaughton et al., 2013).

\section{The convergence of stakeholders}

The following section presents data that demonstrate the consequences of bringing together different stakeholders in community-based research, a defining characteristic of CBR (Israel et al., 1998). In HIV CBR these partners are all meant to be equitably involved in project planning and development (2012a). Many participants prided themselves on their complement of partners:

We had the community health centres involved, the $[\mathrm{X}]$ bureau was involved, Public Health was involved, we might even have had [high profile politician] on, too, I can't remember. But usually we'd have some provincial [policy] person if we could. (Interview 14, A)

Well this is genuinely multidisciplinary, which is another complication, right? I'm actually a [social scientist], and one is an epidemiologist, the other one is a [basic scientist]. So that's real multidisciplinary, right? (Interview 18, A)

However, bringing together partners from different disciplines and sectors often required a long negotiation process. This participant described a multi-year process to develop and submit a single proposal:

... it took about three years of pre-application phase ... but then ... the frequency of our meetings increased, about once a week as we brainstormed what issues needed to be addressed. What could a research project potentially look like? And certainly after the first year of discussions we agreed that we're a good fit for each other.... (Interview 26, A)

Once partnerships are established, there is the ongoing requirement to nurture and develop these relationships:

I mean the challenges to sort of keep up with all of the projects, I think every researcher has that problem, keeping up with them all because cause when you have a community-based project there are partnerships to maintain and all the projects that are community based have multiple investigators and multiple partners and multiple students and so there's a lot of balls to keep in the air that are different.... (Interview 35, A)

In $\mathrm{CBR}$, time requirements can be particularly onerous and a barrier to conducting actual research (Castleden et al., 2012). However, in the CBR literature there has been little recognition for the way these structures re-enforce dominant power relations and the 'trade-offs' made by the respective actors. The following section attends to this gap with consideration for the consequences for different stakeholders.

\subsection{Academic partners}

A number of academic participants described feeling constrained by expectations in CBR. One participant questioned whether the relationship model imposed in CBR is an appropriate fit with an academic culture that promotes independence:

I'm an academic so my research team is made up mostly of academics but I've also got community-based people on there too, but academics, we're not pack animals, and there's now a whole granting structure that wants us to be pack animals ... it's very hard for us to work together.... (Interview 26, A)

The CIHR (2012) HIV CBR research program describes academic researchers as "contribut[ing] their research expertise in methodology, scientific rigour and supervision of future researchers." This suggests a consultancy role, but researchers often take on considerably more responsibility:

Once people know that you're the one with that education, you're wanted in charge [of] the project, you're hiring them. Like it or not, the person who is doing that has the power. You could try to like sugar coat it and say 'we're all in this together!' But, somebody is getting paid more, somebody is supervising ... with CBR it's assumed 'you just have to really engage with communities and [everything] will be all right,' you know? (Interview 37, A)

This next participant questioned whether these partnerships are undermining researchers' autonomy and the supposed goal of bettering services:

I think sometimes, as they say, the pendulum has swung back to the other end, because it's very stifling in that way because you feel that you cannot say anything because you're going to say something against the grain ... the community is so powerful that if you say something they won't allow you to play in the sandbox anymore ... and it's this weird thing where these agencies desperately need a research presence to justify their existence and yet, with your researcher lens you may see some problems, and wouldn't it be better for everyone if those problems were solved, and yet simply by naming them suddenly you risk their being able to exist? (Interview 16, A)

This participant's narrative highlights the way research is important and necessary to the extent it is able to obtain information about service users that can bring in more program funding, but research that brings into question the organization's effectiveness becomes perceived as a threat.

\subsection{Community partners}

The CIHR (2012) HIV CBR program has tasked "community leaders" with ensuring "that research will lead to practical and 
useful outcomes that will directly benefit the community." However, programmatic conceptions of "community" often overlook the locus of control individual actors have and the diversity of perspectives and agendas within (Jewkes and Murcott, 1998). The following participant described how once a project starts, there are few mechanisms to actually ensure community involvement:

Yeah there's always terms of reference but that doesn't mean I'm gonna have the same amount of influence at a table [as] I want, right? But I'll have to be there to make sure that at least they've heard what I have to say, whether or not they implement it. I don't know how to make people accountable when they don't have to be accountable to me. (Interview 50, C)

This next participant described the impact a project can have on a community as a result of conflict between community partners over who controls the process:

The biggest differences of opinion were between community members themselves. It wasn't so much the academics against the community members, it was the community members fighting with other community members about what was needed and wanted. So this notion of this romanticized homogeneous community that really knows what it wants, didn't so much pan out when you had such a tremendous diversity within community who represents community and what community means and that's where the biggest battles were fought, literally battles, in terms of the notions of control and decision-making. (Interview 33, A)

The processes that researchers and communities have advocated for, and helped design, now serve to discipline them through the requirements for ongoing meetings and negotiations. This administrative function has become paramount as partners jostle for who has more or less influence in the project and whose agenda is being pursued.

\subsection{Peer research assistants}

The opportunities and challenges that result from involving "peer research assistants" (PRAs) were recurrent themes throughout the interviews. The PRA approach involves the recruitment and training of community members with a lived experience of HIV, and/or members of "at risk" communities (injection drug users, sex workers, etc.) to participate in the research process (for a discussion of this approach see Greene et al., 2009; Logie et al., 2012a). While community members are said to want to be openly involved in CBR through PRA positions, this participant described having encountered a different response:

... it was supposed to be that [peers] are empowered enough that they would want to put their name and phone number as a contact on the recruitment flyers, but not one of them did when [it came] down to it because of stigma, which is very real, and I'm not saying that they should have if they didn't feel comfortable, the assumption when I signed on was that these were people that were confident about coming out as being HIV positive. But that was not the reality. (Interview 37, A)

This next quotation demonstrates the ways a neoliberal rhetoric of self-improvement has crept into these initiatives:

These people were all of the margins of society, they were all using [drugs], they were committing crimes ... I mean social violence, social conflict, so there's all kinds of things going on....
So what happened was so beautiful ... they began to change. They were eating better! They were making some small sum of money every week. They had a sense that they weren't just taking from society, they were contributing. They got a sense of value - the research data they were collecting nobody else could collect. Skin improved! Hair improved! None of them was using anymore, they were all on methadone. Housing situation improved! Social conflict decreased! Crime decreased! You know the research became something more than the research. (Interview 7, A)

The issue here is not whether this researcher's claims about the transformative potential of the research accurately reflects the peers' experiences. Indeed, such claims are questionable considering the modest resources and support most CBR projects are able to offer. Rather, the issue is why outcomes related to increased social functioning and productivity are being used to measure success. Guta et al. (2013) have argued these initiatives rely on the rhetoric of harnessing lived experience to produce social change, but function as interventions into the lives of marginalized peers seeking to transform them into more productive citizens. Returning to the earlier discussion of whether CBR can sustain the growth of its engagement strategies, this participant reflected on what happens to PRAs at the end of a project:

[I've] been in the situation a couple of times where you hire them, it's a part-time position, right? Like hourly, and it's not necessarily a lot of hours and it's not a lot of money ... you can't live on that, okay? And it's only a short-term and I've actually seen this a few times where the [peer] research assistant gets a lot of hopes up and they have a lot of expectations and anticipation and then the project's finished and they don't have anything, I've struggled with that. (Interview 32, A)

Chung and Lounsbury (2006) have observed that in HIV CBR failing to reflect on power differentials can lead to "disempowering outcomes" despite otherwise participatory processes.

\section{Discussion}

The results presented above provide further evidence for concerns raised at the beginning of this paper that "inclusion" in scientific decision making is a more complicated undertaking than is often described (Barnett et al., 2012; Braun and Schultz, 2010; Gregory and Lock, 2008). We now turn back to our theoretical interests in governmentality to challenge claims that "scientific citizenship" and related strategies for engaging "communities" in science represent the democratization of knowledge production. Rather, community engagement in research has significant costs for all involved, both in terms of how they are governed (how their conduct is orchestrated) and how they govern each other and themselves. We revisit the governmentality literature to provide a possible explanation of how certain practices within the Canadian HIV CBR movement have come to be. Specifically, we return to Miller and Rose $(2008,63)$ who revised Foucault's definition of governmentality to account for the development of new governmental technologies that operate through "a multitude of connections" and "between the aspirations of authorities and the activities of individuals and groups." The concept of "community," and especially in relation to those defined as "risk groups," has emerged as a "new territory for the administration of individual and collective existence ..." (Ibid, 88).

In HIV CBR, a process has emerged through which community "needs" are translated into research projects bringing academic 
partners and community-based organizations together to produce evidence about communities. Peterson and Lupton (1996, 146-147) have observed that "community participation" has become a duty imbued with regulatory effects. When there is resistance to participation, in this case framed as suspicion towards the motivations of researchers, it is constructed as a knowledge deficit that "needs" to be overcome (Ibid, 154). Community "buy-in" is necessary for these kinds of research initiatives to be successful, providing what Rose $(2000,1403)$ has called a "moral voice" and the authority to enter community spaces. Obtaining this consent necessitates a performance wherein university-based researchers present themselves as "servants" of the community in an effort to better "embod[y] neutrality, authority and skill in a wise figure operating according to an ethical code "beyond good and evil"” (Miller and Rose, 2008, 68). Through the impetus to turn community members into "researchers," governmental technologies are able to reach the most marginalized (sex workers, injection drug users, the homeless, etc.), and through the logic of "empowerment" instill in them the virtues of active citizenship and neoliberal entrepreneurialism (Cruikshank, 1999; Miller and Rose, 2008). We do not mean to suggest that those who undertake this work are disingenuous; rather, Dreyfus and Rabinow $(1982,186)$ have commented that in Foucauldian terms, "power is exercised upon the dominant as well as the dominated; there is a process of selfformation or autocolonization involved." Here, both researchers and community representatives are enticed to enter into these relationships and govern themselves and each other.

For Rose $(2000,1401)$ community has "become the object and target for the exercise of political power while remaining, somehow, external to politics and a counterweight to it." Cruikshank $(1999,117)$ has argued that neoliberal strategies that shift attention from the state to bureaucratic and administrative functions helps to mask power and depoliticize power relationships. The administrative function of CBR, as described above in the process of engagement, negotiation, and continual meetings, serves to depoliticize the issues at stake and shifts the perceived locus of power from the state to the individual partners. This creates conflict and tension between partners, and marginalizes those who are unable or unwilling to play "in the sandbox." Peterson and Lupton (1996, 159) argue that such techniques for "maximizing involvement" discipline individuals to act in conformity with "the administrative model of decision making" and within hierarchical structures. Through accessing specialized funding opportunities developed in partnership with the state, these projects adopt prescribed engagement and partnership strategies to be competitive, and that require a considerable investment of their own time and resources. The emphasis on research with "policy impact" restricts the kinds of research being conducted, the opportunities for engagement, and the terms of that engagement itself. This privileging of research outcomes over process contradicts the core principles of CBR (Israel et al., 1998).

While proponents of CBR claim communities want to have a role in knowledge production, which may certainly be true in some cases, community-based HIV organizations have also had to evolve from their grassroots beginnings to better meet changing community needs and regulatory and funding requirements (Guenter et al., 2005; Roy and Cain, 2001). Early citizenship projects based on activism and radical democracy have been replaced by credentialing and accountability (Brown, 1997; Kinsman, 1996). These organizations' community-development and organizing potential has been re-focused in partnered health promotion and research activities (Chillag et al., 2002; Harris, 2006; Maguire et al., 2004). The most recent neoliberal wave has promoted "evidence-based" decision-making frameworks that require public services to use "the best available research evidence" in program and policy development (Hammersley, 2005; Howlett, 2009; Taylor, 2005). In response to this evidential turn, Canadian voluntary and non-profit sector organizations have been generating their own data to maintain and/or obtain new sources of funding (Grundy and Smith, 2007; Laforest and Orsini, 2005). While the use of research and social science methodologies by community-based organizations provides a potential tool to identify deficits and improve conditions within communities, these methods have also enhanced the state's ability to strategically manage policy decisions (Parsons, 2002). Miller and Rose (2008,65-68) have argued such forms of inscription and the collection of evidence are central aspects of modern governance and serve to enrol these organizations into social, economic, and political processes without being seen to encroach on their "freedom." These community-based organizations remain competitive to the extent that they can claim to attract groups targeted by the state for intervention.

Growing expectations and fewer resources within the research and service sector turn those with similar interests and mandates into competitors. Drawing on early AIDS activism, Cruikshank $(1999,67)$ has argued that "technologies of citizenship" "link the subjectivity of citizens to their subjection, and link activism to discipline." Miller and Rose $(2008,93)$ further argue that community governance, "even when it works upon pre-existing bonds of allegiance," reshapes these bonds and imbues allegiances with values and expertise that create new forms of exclusion. Scientific citizenship provides another way of packaging discipline, but is especially effective within HIV CBR because "community" is understood as a natural and apolitical space for organizing (Rose, 1999, 2000). The impetus to produce evidence can be attributed to what Miller and Rose $(2008,67)$ have described as "action at a distance" that "install[s] a calculative technology." Conducting research, defined in myriad ways by funders, researchers, and service sector representatives who have been consulted, has made it possible for community-based organizations to come to certain conclusions about '“where they are,' [to] calibrate themselves in relation to where they should be, and devise ways of getting from one state to the other" (Ibid, 67). This is a form of indirect governance that does not enforce particular practices, but instead relies on organizations to produce evidence about themselves and each other that will result in the same ends. For Miller and Rose (2008, 107) this emphasis on measurements and outcomes manages not only "professional-client relations," but also the professionals involved. This is a way of governing communities, agencies, and various individual stakeholders all through the production of evidence and their participation in research.

The preceding analysis focused on the influence of neoliberalism and the material consequences for the actors involved in the HIV CBR movement. While these neoliberal trends have been welldocumented, if not previously in relation to CBR, the literature has generally overlooked Foucault's (2007) interest in modes of security. In this final section we consider the relation between CBR and the broader securitization of HIV. Responses to health issues like HIV do not emerge haphazardly; funding does not "serendipitously" appear as some participants in this study claimed. Rather, the HIV CBR program is "a key component of CIHR's commitment through the Government of Canada's Federal Initiative to Address HIV/AIDS" and "provides leadership and direction for the research portion of the Federal Initiative" (CIHR, 2012c). The "Federal Initiative" is itself part of the Public Health Agency of Canada (PHAC) and "provides funding for prevention and support programs reaching key priority populations, as well as research, surveillance, public awareness, and evaluation" (PHAC, 2012). The Federal Initiative further provides an organizing hub through which PHAC, Health Canada, the CIHR, and Correctional Service Canada are able to "collaborate" with various partners in the HIV response. Combating 
HIV becomes the central feature in a "milieu" that links actors within an "apparatus of security" (Foucault, 2007, 21). Elbe (2005, 2009 , 2010) has identified similar securitization processes, and the convergence of stakeholders, operating globally to re-shape the HIV treatment and prevention response.

Through a securitization lens, we see that the HIV CBR program fills an important role in the process of normalizing knowledge about HIV and affected communities, while also determining the multi-stakeholder response. Through partnership building, various actors are made "stakeholders" and are brought together to construct "communities" for targeted interventions. This process of documenting and classifying "community" practices, beliefs, and shared networks through social scientific methods is part of a biopolitical process of demarcating between those who, in Foucault's (1978, 2003b) terms, the state should "make live and let die." Building on Foucault, Esposito (2011, 9) has described bio-politics as the state's efforts to "immunize" itself against threats like HIV by constructing divisive notions of community and the other: "immunity constitutes or reconstitutes community precisely by negating it." The Canadian government's funding cuts to HIV programs that oppose its policies (Paperny, 2012), and fighting expensive legal battles to close others it deems morally problematic (Fafard, 2012), while actively scaling-up the HIV CBR program (CIHR, 2012b) are examples of this "immunizing." Communities are researched not to improve their conditions, but to protect the collective from them. While critics might counter that too much is being made of this small program, it is worth reiterating that the HIV CBR program is identified as a model of citizen engagement (CIHR, 2009). This analysis has implications for understanding the deployment of initiatives seeking to engage communities in health research throughout the CIHR and beyond to other comparable research funding institutions with direct ties to the state.

\section{Conclusion}

The conclusion drawn from this analysis is that the HIV CBR movement serves governmental ends by collecting 'needed' surveillance data and keeping potentially critical voices occupied through increasingly elaborate funding requirements. If our analysis has erred on the side of exposing domination at the expense of inculcating forms of resistance, it stands in opposition to the often uncritical praise accompanying CBR. This should not be taken to suggest an absence of critical voices in the movement; indeed, many have been privileged in this analysis. The question raised is how should those in the movement respond to the narrowing of opportunities? Or, in Foucault's terms, what are the opportunities for "counter-conduct" by those who are governed? (Davidson, 2011). Surely we cannot return to the beginnings of the epidemic when scientists worked in isolation and communities were actively excluded. However, as HIV CBR becomes redefined as tool to promote new biomedical prevention technologies (Wilton, 2012) it is worth asking, as Flicker (2008) has done, who is really benefiting? Could the networks and partnerships established for CBR be deployed in different ways? Researchers and communities need to turn their collective gaze past the constructed borders of "community relevance" towards the governmental institutions whose inaction fuels the spread of HIV in Canada and beyond. As early AIDS activism proved, change is possible, with the caveat that ongoing hyper-vigilance is needed to challenge governmental cooptation.

\section{Acknowledgements}

We wish to acknowledge the participants who shared their time and rich insights, members of our larger research team: Robb
Travers, Michael G. Wilson, Stephanie Nixon, Catherine Worthington, Sarah Fielden, Jacquie Gahagan, and Claudia Mitchell.

Funding for this research was provided by the Canadian Institutes of Health Research (CIHR). Adrian Guta is supported by a CIHR Postdoctoral Fellowship in Health Services/Population Health HIV/AIDS Research, and a CIHR fellowship in Health Care, Technology and Place (HCTP).

\section{References}

Ahmed, S.M., Palermo, A.-G.S., 2010. Community engagement in research: frameworks for education and peer review. Am. J. Public Health 100, 1380-1387.

Allman, D., Myers, T., Cockerill, R., 1997. Concepts, Definitions and Models for Community-based HIV Prevention Research HIV Social. Behavioural and Epidemiological Studies Unit, University of Toronto.

Altman, D., 1994. Power and Community: Organizational and Cultural Responses to AIDS. Taylor \& Francis, London; Bristol, PA.

Bäckstrand, K., 2003. Civic science for sustainability: reframing the role of experts, policy-makers and citizens in environmental governance. Glob. Environ. Polit. 3, 24-41.

Barnett, J., Burningham, K., Walker, G., Cass, N., 2012. Imagined publics and engagement around renewable energy technologies in the UK. Public Underst. Sci. 21, 36-50.

Bauer, G.R., Travers, R., Scanlon, K., Coleman, T.A., 2012. High heterogeneity of HIVrelated sexual risk among transgender people in Ontario, Canada: a provincewide respondent-driven sampling survey. BMC public health 12, 292.

Bickerstaff, K., Lorenzoni, I., Jones, M., Pidgeon, N., 2010. Locating scientific citizenship: the institutional contexts and cultures of public engagement. Sci. Technol. Hum. Values 35, 474-500.

Boivin, A., Currie, K., Fervers, B., Gracia, J., James, M., Marshall, C., et al., 2010. Patient and public involvement in clinical guidelines: international experiences and future perspectives. Qual. Saf. Health Care 19, 1-4.

Bonney, R., Shirk, J.L., Phillips, T.B., Wiggins, A., Ballard, H.L., Miller-Rushing, A.J., et al., 2014. Next steps for citizen science. Science 343, 1436-1437.

Braun, K., Schultz, S., 2010. “... a certain amount of engineering involved”: constructing the public in participatory governance arrangements. Public Underst. Sci. 19, 403-419.

Brown, M.P., 1997. Replacing Citizenship: AIDS Activism and Radical Democracy. Guilford Press.

Bunton, R., Petersen, A.R., 1997. Foucault, Health and Medicine. Routledge, London ; New York.

Burchell, G., Gordon, C., Miller, P. (Eds.), 1991. The Foucault Effect: Studies in Governmentality: With Two Lectures by and an Interview with Michel Foucault. University of Chicago Press, Chicago, IL.

Canadian Institutes of Health Research, 2009. CIHR's Framework for Citizen Engagement: Partnerships and Citizen Engagement Branch. Canadian Institutes of Health Research, Ottawa, Canada.

Canadian Institutes of Health Research, 2012a. CIHR HIV/AIDS Community-based Research Program.

Canadian Institutes of Health Research, 2012b. Harper Government Supports New Research on HIV/AIDS.

Canadian Institutes of Health Research, 2012c. HIV/AIDS Community-based Research Program.

Canadian Institutes of Health Research, 2012d. About the HIV/AIDS CommunityBased Research Program. Retrieved July 15th 2014: http://www.cihr-irsc.gc.ca/ e/40943.html\#1.

Castleden, H., Morgan, V.S., Lamb, C., 2012. "I spent the first year drinking tea": exploring Canadian university researchers' perspectives on community-based participatory research involving indigenous peoples. Can. Geogr./Le. Géogr. Can. 56, 160-179.

Chau, T.S., Islam, N., Tandon, D., Ho-Asjoe, H., Rey, M., 2007. Using community-based participatory research as a guiding framework for health disparities research centers. Prog. Commu. Health Partnersh.: Res. Educ. Action 1, 195-205.

Chillag, K., Bartholow, K., Cordeiro, J., Swanson, S., Patterson, J., Stebbins, S., et al. 2002. Factors affecting the delivery of HIV/AIDS prevention programs by community-based organizations. AIDS Educ. Prev. 14, 27-37.

Chung, K., Lounsbury, D.W., 2006. The role of power, process, and relationships in participatory research for statewide HIV/AIDS programming. Soc. Sci. Med. 63, 2129-2140.

Clarke, A., 2005. Situational Analysis Grounded Theory after the Postmodern Turn. Sage Publications, Thousand Oaks, California.

Comaroff, J., 2007. Beyond bare life: AIDS, (Bio)politics, and the neoliberal order. Public Cult. 19, 197-219.

Conway, S., Crawshaw, P., Bunton, R., 2007. "There is a mantra of:"community involvement is good", and we all tick the boxes and say we have done the consultation': health action zones and the normative principles of government. Soc. Theory \& Health 5, 208-227.

Cooke, B., Kothari, U., 2001. Participation: the New Tyranny? Zed Books.

Cruikshank, B., 1999. The Will to Empower: Democratic Citizens and Other Subjects. Cornell University Press, Ithaca, NY.

Davidson, A.I., 2011. In praise of counter-conduct. Hist. Hum. Sci. 24, 25-41. 
Dean, M., 2010. Governmentality: Power and Rule in Modern Society. SAGE, Los Angeles.

Dreyfus, H.L., Rabinow, P., 1982. Michel Foucault: Beyond Structuralism and Hermeneutics. University of Chicago Press, Chicago.

Elam, M., Bertilsson, M., 2003. Consuming, engaging and confronting science: the emerging dimensions of scientific citizenship. Eur. J. Soc. Theory 6, 233-251.

Elbe, S., 2005. AIDS, security, biopolitics. Int. Relations 19, 403-419.

Elbe, S., 2009. Virus Alert : Security, Governmentality, and the AIDS Pandemic. Columbia University Press, New York.

Elbe, S., 2010. Security and Global Health: Towards the Medicalization of Insecurity. Polity Press, Cambridge; Malden, Mass.

Epstein, S., 1996. Impure Science: AIDS, Activism, and the Politics of Knowledge. University of California Press, Berkeley.

Esposito, R., 2011. Immunitas: the Protection and Negation of Life. Polity Press, Cambridge, Eng.; Malden, MA.

Fafard, P., 2012. Public health understandings of policy and power: lessons from INSITE. J. urban health: Bull. N.Y. Acad. Med. 89, 905-914.

Finn, M., Sarangi, S., 2008. Quality of life as a mode of governance: NGO talk of HIV 'positive'health in India. Soc. Sci. Med. 66, 1568-1578.

Flicker, S., 2008. Who benefits from community-based participatory research? A case study of the positive Youth project. Health Educ. Behav. 35, 70-86.

Flynn, R., 2002. Clinical governance and governmentality. Health, Risk Soc. 4, 155-173.

Foucault, M., 1978. The History of Sexuality: an Introduction. Vintage Books, New York.

Foucault, M., 1980. Power/Knowledge: Selected Interviews and Other Writings. Random House of Canada, Toronto.

Foucault, M., 1988. An aesthetics of existence. In: Kritzman, L.D. (Ed.), Politics, Philosophy, Culture: Interviews and Other Writings, 1977-1984. Routledge, New York, pp. 47-54.

Foucault, M., 2003a. The essential foucault: Selections from essential works of foucault, 1954-1984. In: Rabinow, P., Rose, N. (Eds.). The New Press, New York.

Foucault, M., 2003b. "Society Must Be Defended": Lectures at the College De France 1975-1976. Picador, New York.

Foucault, M., 2005. The Hermeneutics of the Subject: Lectures at the College de France 1981-1982. Picador, New York.

Foucault, M., 2007. Security, Territory, Population: Lectures at the Collège de France, 1977-1978. Palgrave Macmillan, Basingstoke [England].

Foucault, M., 2010a. The Birth of Biopolitics: Lectures at the Collège de France, 1978-1979. Picador, New York.

Foucault, M., 2010b. The Government of Self and Others: Lectures at the College de France, 1982-1983. Palgrave Macmillan, Houndmills, Basingstoke.

Fries, C.J., 2008. Governing the health of the hybrid self: integrative medicine, neoliberalism, and the shifting biopolitics of subjectivity. Health Sociol. Rev. 17, 353-367.

Geary, A.M., 2007. Culture as an object of ethical governance in AIDS prevention. Cult. Stud. 21, 672-694.

George, C., Adam, B.A., Read, S.E., Husbands, W.C., Remis, R.S., Makoroka, L., et al., 2012. The MaBwana Black men's study: community and belonging in the lives of African, Caribbean and other Black gay men in Toronto. Cult. Health \& Sex. 14, 549-562.

Green, L., Daniel, M., Novick, L., 2001. Partnerships and Coalitions for communitybased research. Public Health Rep. 116 (Suppl. 1), 20-31.

Green, L., Mercer, S., 2001. Can public health researchers and agencies reconcile the push from funding bodies and the pull from communities? Am. J. Public Health 91, 1926-1929.

Greene, S., Ahluwalia, A., Watson, J., Tucker, R., Rourke, S.B., Koornstra, J., et al., 2009. Between skepticism and empowerment: the experiences of peer research assistants in HIV/AIDS, housing and homelessness community-based research. Int. J. Soc. Res. Methodol. 12, 361-373.

Greene, S., Tucker, R., Rourke, S.B., Monette, L., Koornstra, J., Sobota, M., et al., 2010. "Under My Umbrella": the housing experiences of HIV positive parents who live with and care for their children in Ontario. Arch. Women's Ment. health 13, 223-232.

Gregory, J., Lock, S.J., 2008. The Evolution of 'Public understanding of science': public engagement as a tool of science policy in the UK. Sociol. Compass 2, $1252-1265$.

Grundy, J., Smith, M., 2007. Activist knowledges in queer politics. Econ. Soc. 36, 294-317.

Guenter, D., Majumdar, B., Willms, D., Travers, R., Browne, G., Robinson, G., 2005. Community-based HIV education and prevention workers respond to a changing environment. J. Assoc. Nurses AIDS Care 16, 29-36.

Guta, A., Flicker, S., Roche, B., 2013. Governing through community allegiance: a qualitative examination of peer research in community-based participatory research. Crit. Public Health, 1-20.

Guta, A., Murray, S.J., McClelland, A., 2011. Global AIDS governance, biofascism, and the difficult freedom of expression. APORIA: Nurs. J. 3, 15-29.

Hamann, T.H., 2009. Neoliberalism, governmentality, and ethics. Foucault Stud. 6, 37-59.

Hammersley, M., 2005. Is the evidence-based practice movement doing more good than harm? Reflections on Iain Chalmers' case for research-based policy making and practice. Evid. Policy: J. Res. Debate Pract. 1, 85-100.

Harris, G., 2006. Practicing HIV/AIDS community-based research. AIDS Care 18, $731-738$.

Holmes, D., Gastaldo, D., 2002. Nursing as means of governmentality. J. Adv. Nurs. 38, 557-565.
Horowitz, C.R., Robinson, M., Seifer, S.D., 2009. Community-based participatory research from the margin to the mainstream: are researchers prepared? Circulation 119, 2633-2642.

Howlett, M., 2009. Policy analytical capacity and evidence-based policy-making: lessons from Canada. Can. Public Adm. 52, 153-175.

Irwin, A., 2001. Constructing the scientific citizen: science and democracy in the biosciences. Public Underst. Sci. 10, 1-18.

Israel, B., Eng, E., Schulz, A.J., Parker, E.A., 2005. Methods in Community-based Participatory Research for Health. JOssey-Bass, San Francisco.

Israel, B., Schulz, A., Parker, E., Becker, A., 1998. Review of community-based research: assessing partnership approaches to improve public health. Annu. Rev. Public Health 19, 173-194.

Israel, B., Schulz, A., Parker, E., Becker, A., 2001. Community-based participatory research: policy recommendations for promoting a partnership approach in health research. Educ. Health 14, 182-197.

Jackson, R., Barbagallo, F., Haste, H., 2005. Strengths of public dialogue on sciencerelated issues. Crit. Rev. Int. Soc. Polit. Philos. 8, 349-358.

Jagosh, J., Macaulay, A.C., Pluye, P., Salsberg, J., Bush, P.L., Henderson, J., et al., 2012 Uncovering the benefits of participatory research: implications of a realist review for health research and practice. Milbank Q. 90, 311-346.

Jewkes, R., Murcott, A., 1998. Community representatives: representing the "community"? Soc. Sci. Med. 46, 843-858.

Jones, L., Wells, K., 2007. Strategies for academic and clinician engagement in community-participatory partnered research. Jama 297, 407-410.

Kinsman, G., 1996. 'Responsibilty’as a strategy of governance: regulating people living with AIDS and lesbians and gay men in Ontario. Int. J. Hum. Resour. Manag. 25, 393-409.

Kone, A., Sullivan, M., Senturia, K., Chrisman, J., Ciske, S., Krieger, J., 2000. Improving collaboration between researchers and communities. Public Health Rep. 115 $243-248$.

Laforest, R., Orsini, M., 2005. Evidence-based engagement in the voluntary sector: lessons from Canada. Soc. Policy \& Adm. 39, 481-497.

Larner, W., Craig, D., 2005. After neoliberalism? Community activism and local partnerships in Aotearoa New Zealand. Antipode 37, 402-424.

Lavery, J.V., Tinadana, P.O., Scott, T.W., Harrington, L.C., Ramsey, J.M., YtuarteNuñez, C., et al., 2010. Towards a framework for community engagement in global health research. Trends Parasitol. 26, 279-283.

Logie, C., James, L., Tharao, W., Loutfy, M.R., 2012a. Opportunities, ethical challenges and lessons Learned from working with peer research assistants in a multimethod HIV community-based research study in Ontario, Canada. J. Empir Res. Hum. Res. Ethics: Int. J. 7, 10-19.

Logie, C., James, L., Tharao, W., Loutfy, M.R., 2012b. "We don't exist”: a qualitative study of marginalization experienced by HIV-positive lesbian, bisexual, queer and transgender women in Toronto, Canada. J. Int. Aids Soc. 15, 17392.

Lupton, D., Tulloch, J., 1998. The adolescent 'unfinished body', reflexivity and HIV/ AIDS risk. Body Soc. 4, 19-34.

Macnaughton, E., Nelson, G., Goering, P., 2013. Bringing politics and evidence together: policy entrepreneurship and the conception of the at Home/Chez So Housing First Initiative for addressing homelessness and mental illness in Canada. Soc. Sci. Med. 82, 100-107.

Maguire, S., Hardy, C., Lawrence, T.B., 2004. Institutional entrepreneurship in emerging fields: HIV/AIDS treatment advocacy in Canada. Acad. Manag. J. 47, 657-679.

Mayer, S., 2003. Science out of step with the public: the need for public accountability of science in the UK. Sci. Public Policy 30, 177-181.

McClelland, A., Flicker, S., Nepveux, D., Nixon, S., Vo, T., Wilson, C., et al., 2012 Seeking safer sexual spaces: queer and trans young people labeled with intellectual disabilities and the paradoxical risks of restriction. J. Homosex. 59, 808-819.

McGregor, S., 2001. Neoliberalism and health care. Int. J. Consumer Stud. 25, 82-89.

Miller, P., Rose, N.S., 2008. Governing the Present : Administering Economic, Social and Personal Life. Polity, Cambridge.

Minkler, M., 2005. Community-based research partnerships: challenges and opportunities. J. Urban Health 82, ii3-ii12.

Minkler, M., Wallerstein, N. (Eds.), 2008. Community-based Participatory Research for Health. Jossey-Bass, San Francisco, CA.

Mitton, C., Smith, N., Peacock, S., Evoy, B., Abelson, J., 2009. Public participation in health care priority setting: a scoping review. Health policy 91, 219-228.

Mosavel, M., Simon, C., van Stade, D., Buchbinder, M., 2005. Community-based participatory research (CBPR) in South Africa: engaging multiple constituents to shape the research question. Soc. Sci. Med. 61, 2577-2587.

Mykhalovskiy, E., McCoy, L., Bresalier, M., 2004. Compliance/adherence, HIV, and the critique of medical power. Soc. Theory \& Health 2, 315-340.

National Institutes of Health. Community-Based Participatory Research. Retrieved July 15, 2014, from National Institutes of Health: http://obssr.od.nih.gov/ scientific_areas/methodology/community_based_participatory_research/index. aspx.

Nguyen, V.-K., 2010. The Republic of Therapy: Triage and Sovereignty in West Africa's Time of AIDS. Duke University Press, Durham [N.C.].

O’Doherty, K.C., Burgess, M.M., 2009. Engaging the public on Biobanks: outcomes of the BC Biobank Deliberation. Public Health Genom. 12, 203-215.

Ogden, R., 1999. Report on Research Ethics Review in Community-based HIV/AIDS Research. http://cbr.cbrc.net/files/1029213009/Ogden\%20Ethics\%20Report.pdf. Vancouver, BC: Canadian HIV/AIDS Legal Network under contract with AIDS Vancouver. 
Paperny, A.M., 2012. Fearing Advocacy, Ottawa Rejects HIV/AIDS Funding Proposals the Globe \& Mail.

Parker, R., Aggleton, P., 2003. HIV and AIDS-related stigma and discrimination: a conceptual framework and implications for action. Soc. Sci. Med. 57, $13-24$.

Parsons, W., 2002. From muddling through to muddling up - evidence based policy making and the modernisation of British government. Public Policy Adm. 17, 43-60.

Petersen, A., 2003. Governmentality, critical scholarship, and the medical humanities. J. Med. Humanit. 24, 187-201.

Petersen, A., Lupton, D., 1996. The New Public Health: Health and Self in the Age of Risk. Sage Publications, London.

Public Health Agency of Canada, 2012. Federal Initiative to Address HIV/AIDS in Canada. Public Health Agency of Canada, Ottawa.

Rhodes, S.D., Malow, R.M., Jolly, C., 2010. Community-based participatory research (CBPR): a new and not-so-new approach to HIV/AIDS prevention, care, and treatment. AIDS Educ. Prev. 22, 173.

Roche, B., 2008. New Directions in Community-based Research. Wellesley Institute, Toronto.

Rose, N., 1999. Powers of Freedom: Reframing Political Thought. Cambridge University Press.

Rose, N., 2000. Community, citizenship, and the third way. Am. Behav. Sci. 43, 1395-1411.

Rose, N., O'Malley, P., Valverde, M., 2006. Governmentality. Annu. Rev. Law Soc. Sci. $2,83-104$

Roy, C., Cain, R., 2001. The involvement of people living with HIV/AIDS in community-based organizations: contributions and constraints. AIDS Care 13, $421-432$.

Schensul, J.J., 1999. Organizing community research partnerships in the struggle against AIDS. Health Educ. Behav. 26, 266-283.

Silversides, A., 2003. AIDS Activist: Michael Lynch and the Politics of Community. Between the Lines, Toronto.

Silvestre, A.J., Quinn, S.J., Rinaldo, C.R., 2010. A 22-year-old community advisory board: health research as an opportunity for social change. J. Commun. Pract. $18,58-75$.
Simon, C.M., Newbury, E., Heureux, J.L., 2011. Protecting participants, promoting progress: public perspectives on community advisory boards (CABs) in biobanking. J. Empir. Res. Hum. Res. Ethics: Int. J. 6, 19-30.

Taylor, D., 2005. Governing through evidence: participation and power in policy evaluation. J. Soc. Policy 34, 601-618.

Teghtsoonian, K., 2009. Depression and mental health in neoliberal times: a critical analysis of policy and discourse. Soc. Sci. Med. 69, 28-35.

The Centers for Disease Control and Prevention, 2011. In: T.C.f.D.C.a. Prevention (Ed.), National Community Committee - Fact Sheet. National Center for Chronic Disease Prevention and Health Promotion.

Travers, R., Wilson, M., Flicker, S., Guta, A., Bereket, T., McKay, C., et al., 2008. The greater involvement of people living with AIDS principle: theory versus practice in Ontario's HIV/AIDS community-based research sector. AIDS Care 20, 615-624.

Viswanathan, M., Ammerman, A., Eng, E., Garlehner, G., Lohr, K.N., Griffith, D., et al., 2004. Community-based participatory research: assessing the evidence. Evid. Report/Technology Assess., 1-8.

Wallerstein, N., Duran, B., 2006. Using community-based participatory research to address health disparities. Health Promot. Pract. 7, 312-323.

Walters, W., 2012. Governmentality: Critical Encounters. Routledge, New York.

Waring, J., 2007. Adaptive regulation or governmentality: patient safety and the changing regulation of medicine. Sociol. Health \& Illn. 29, 163-179.

Wiggins, A., Crowston, K., 2011. From conservation to crowdsourcing: a typology of citizen science. In: System Sciences (HICSS), 2011 44th Hawaii International Conference. IEEE, pp. 1-10.

Wilton, J., 2012. CBR Musings: Moving Research on New "Biomedical" HIV Prevention Technologies into Practice. Pacific AIDS Network.

Winch, S., 2005. Ethics, government and sexual health: insights from Foucault. Nurs. Ethics 12, 177-186.

Woolford, A., Curran, A., 2013. Community positions, neoliberal dispositions: managing nonprofit social services within the bureaucratic field. Crit. Sociol. 39, 45-63.

Wynne, B., 2006. Public engagement as a means of restoring public trust in science - hitting the notes, but missing the music? Community Genet. 9, 211-220. 